\title{
Risks of ovarian, breast, and corpus uteri cancer in women treated with assisted reproductive technology in Great Britain, 1991-2010: data linkage study including 2.2 million person years of observation
}

\author{
Carrie L Williams, ${ }^{1}$ Michael E Jones, ${ }^{2}$ Anthony J Swerdlow, ${ }^{2}$ Beverley J Botting, ${ }^{1}$ \\ Melanie C Davies, ${ }^{3}$ Ian Jacobs, ${ }^{3,4}$ Kathryn J Bunch, ${ }^{5}$ Michael F G Murphy, ${ }^{6}$ Alastair G Sutcliffe ${ }^{1}$
}

${ }^{1} \mathrm{UCL}$ Great Ormond Street Institute of Child Health,

London, UK

${ }^{2}$ Institute of Cancer Research,

London, UK

Institute for Women's Health,

University College London

Hospitals, London, UK

${ }^{4}$ University of New South Wales, Sydney, NSW, Australia

${ }^{5}$ National Perinatal

Epidemiology Unit, University of

Oxford, Oxford, UK

${ }^{6}$ Nuffield Department of

Obstetrics and Gynaecology,

University of Oxford, Oxford, UK

Correspondence to:

Prof A G Sutcliffe,

Policy, Practice and Population

Unit, UCL Great Ormond Street

Institute of Child Health,

University College London,

London WC1N 1EH, UK

a.sutcliffe@ucl.ac.uk

(or @AlastairSutclif on Twitter;

ORCID 0000-0001-8542-6155)

Cite this as: $B M J$ 2018;362:k2644 http://dx.doi.org/10.1136/bmj.k2644

Accepted: 4 June 2018

\section{ABSTRACT}

OBJECTIVE

To investigate the risks of ovarian, breast, and corpus uteri cancer in women who have had assisted reproduction.

DESIGN

Large, population based, data linkage cohort study.

SETTING AND PARTICIPANTS

All women who had assisted reproduction in Great

Britain, 1991-2010, as recorded by the Human

Fertilisation and Embryology Authority (HFEA).

INTERVENTIONS

HFEA fertility records for cohort members were linked to national cancer registrations.

\section{MAIN OUTCOME MEASURES}

Observed first diagnosis of ovarian, breast, and corpus uteri cancer in cohort members were compared with age, sex, and period specific expectation. Standardised incidence ratios (SIRs) were calculated by use of age, sex, and period specific national incidence rates.

\section{RESULTS}

255786 women contributed 2257789 person years' follow-up. No significant increased risk of corpus uteri cancer (164 cancers observed $v 146.9$ cancers expected; SIR 1.12, 95\% confidence interval 0.95 to 1.30 ) was found during an average of 8.8 years'

\section{WHAT IS ALREADY KNOWN ON THIS TOPIC}

Risks of reproductive cancers in women who have undergone assisted reproduction procedures are uncertain

Some previous studies have suggested a possible increased risk of breast cancer in women treated at younger ages and with multiple cycles; previous studies investigating endometrial cancer risk are underpowered

Early studies suggested increased risks of ovarian cancer in these women, while more recent studies are more reassuring, although inconsistent, regarding any increase in borderline ovarian tumours

\section{WHAT THIS STUDY ADDS}

In this large population based study, endometrial cancer was not increased in women who had assisted reproduction in Great Britain in 1991-2010 when compared with the general population

The risk of breast cancer overall and of invasive breast cancer was not increased, but there was a small increased risk of in situ breast cancer

Increased risks of ovarian cancer, both invasive and borderline, were observed but limited to women with other known risk factors; these findings require further investigation

follow-up. This study found no significantly increased risks of breast cancer overall ( 2578 v 2641.2; SIR $0.98,0.94$ to 1.01$)$ or invasive breast cancer $(2272$ $v$ 2371.4; SIR 0.96, 0.92 to 1.00). An increased risk of in situ breast cancer (291 v 253.5; SIR 1.15, 1.02 to 1.29; absolute excess risk (AER) 1.7 cases per 100000 person years, $95 \%$ confidence interval 0.2 to 3.2) was detected, associated with an increasing number of treatment cycles $(P=0.03)$. There was an increased risk of ovarian cancer ( 405 v 291.82; SIR $1.39,1.26$ to 1.53 ; AER 5.0 cases per 100000 person years, 3.3 to 6.9 ), both invasive ( $264 \mathrm{v} 188.1$; SIR 1.40, 1.24 to 1.58; AER 3.4 cases per 100000 person years, 2.0 to 4.9$)$ and borderline (141 $v$ 103.7; SIR $1.36,1.15$ to 1.60 ; AER 1.7 cases per 100000 person years, 0.7 to 2.8 ). Increased risks of ovarian tumours were limited to women with endometriosis, low parity, or both. This study found no increased risk of any ovarian tumour in women treated because of only male factor or unexplained infertility.

\section{CONCLUSIONS}

No increased risk of corpus uteri or invasive breast cancer was detected in women who had had assisted reproduction, but increased risks of in situ breast cancer and invasive and borderline ovarian tumours were found in this study. Our results suggest that ovarian tumour risks could be due to patient characteristics, rather than assisted reproduction itself, although both surveillance bias and the effect of treatment are also possibilities. Ongoing monitoring of this population is essential.

\section{Introduction}

Assisted reproduction cycles usually involve exposure to supraphysiological levels of oestradiol, exogenous gonadotropins, and multiple ovarian punctures, all potentially carcinogenic. ${ }^{12}$ Most concern surrounds the risks of breast, endometrial, and ovarian cancers after such exposures..$^{3-16}$

Studies investigating breast cancer risks in women who underwent assisted reproduction are inconsistent. ${ }^{3-12}$ Although some studies have shown an increased risk, ${ }^{17}$ most studies do not show an overall increase of breast cancer in exposed women. ${ }^{3-8} 10$ However, some suggest a possible increased risk within subgroups, ${ }^{89}$ including women treated at younger ages ${ }^{9}$ and with multiple cycles. ${ }^{8}$ Most studies investigating endometrial cancer risk in exposed populations have not found a significant increased risk. ${ }^{346718}$ However, most studies have provided very imprecise estimates 
due to small sample size and few events. ${ }^{34618}$ One study suggested an increased risk of endometrial cancer associated with exposure to gonadotrophins, commonly used as part of assisted reproductive technology. ${ }^{19}$ Some early studies investigating fertility drugs used alone, such as single agent oral clomifene, suggested increased risks of ovarian cancer. ${ }^{20}$ Others found no association between fertility drugs and ovarian cancer risk. ${ }^{21}$ Recent investigations into their use as part of assisted reproduction have generally been more reassuring, but remain inconsistent and at risk of bias. ${ }^{4511}$ Some $^{1314}$ but not all studies ${ }^{6}$ have found an increase in borderline tumours.

Given previous inconsistent results, small study size, and lack of information on potential confounders, we undertook a population based linkage study in Britain to provide risk estimates for ovarian, breast, and corpus uteri cancer, in a cohort of over 266000 women undergoing assisted reproduction, with information on potential confounders such as parity and infertility diagnosis.

\section{Methods}

\section{Study population}

We defined assisted reproduction as "treatments or procedures that include in vitro handling of both human oocytes and sperm or embryos, for the purpose of reproduction."22 Records for all women undergoing assisted reproduction from January 1991 to September 2009, and those undergoing the same from October 2009 to December 2010 who gave their prospective consent, in England, Wales, and Scotland were obtained from the Human Fertilisation and Embryology Authority (HFEA).

UK law mandates reporting of all assisted reproduction cycles to the HFEA. For cycles performed before October 2009, research use of these data was permitted, but consent could be withdrawn retrospectively. Fewer than 300 women had done so before this study began (based on the level of reporting detail provided by the HFEA). The study cohort, January 1991 to September 2009, therefore represents about $99.7 \%$ of the at-risk population. For cycles performed October 2009 onwards, prospective consent was required. Overall consent was not provided for an estimated $7 \%$ of women undergoing assisted reproduction in 1991-2010 (about 20000 women, based on reports from the HFEA), who were therefore not included in this study, representing a loss of less than $1 \%$ of person years' follow-up (figure S1, supplementary appendix).

\section{Outcome data}

HFEA records were linked to the National Health Service Central Registers of England, Wales, and Scotland (from which emigrations, deaths, and cancer registrations are reported to authorised medical researchers) in a one-off linkage. Completeness and accuracy of these registers have been described. ${ }^{23-25}$ Overall, records of 266787 (95.1\%) eligible women were linked (box S1 and figure S1, supplementary appendix). Cancer diagnosis date, topography code (ICD-9/ICD-10 (international classification of diseases, 9th and 10th revisions)), morphology (ICD-O-2/ ICD-0-3 (international classification of diseases for oncology, second and third revisions)), and behaviour (ICD-O-2/ICD-0-3) were available where an incident cancer was diagnosed. Women with cancer diagnoses (including non-melanoma skin cancer) recorded before the first treatment year were excluded from analyses. We obtained data relating to potential confounding factors such as infertility diagnosis, parity (as recorded at last treatment cycle completion), and treatment details (including number of stimulated cycles and age at first treatment) for each cohort member from the HFEA database. These data are a combination of patient reported and clinic reported information (table S1). Information regarding infertility diagnoses are reported to the HFEA by assisted reproduction clinics, based on investigations undertaken by that clinic; by the referring clinician; or occasionally by patient self report.

\section{Statistical analyses}

Follow-up was calculated from date of first treatment (estimated as the mid-point of the first treatment year) until the date of any cancer diagnosis, death, emigration, or study end (March 2011), whichever came first. For analyses involving number of cycles, infertility duration, and live and multiple births, person years at risk were calculated from date of last treatment (estimated as mid-point of the last treatment year), because the HFEA did not record intermediate dates required for time dependent analysis. To calculate expected cancers, we multiplied the person years at risk by corresponding national incidence rates (by 5 year age band and individual calendar year) for the general female population of England and Wales.

Standardised incidence ratios were calculated by the comparison of observed values with expected values. We calculated 95\% confidence intervals, two sided P values, and trends assuming a Poisson distribution. ${ }^{26}$ Sensitivity analyses excluded the first 12 months of follow-up, to investigate potential surveillance bias in the period immediately following assisted reproductive treatment (which could arise as a result of treatment and or after-care; supplementary appendix). Absolute excess risks represent an estimate of the increased risk in the study group as compared with the general population and gives a direct measure of excess risk. They are presented per 100000 person years, with corresponding 95\% confidence intervals, based on exact confidence intervals for Poisson counts. Analyses were performed using Stata, version $12 .{ }^{27}$

\section{Patient involvement and study approval}

Representatives from patient support groups were consulted on the original research question, design, and planning of this study. Approval of the study and waiver of the requirement for individual consent were obtained from the UK Health Research Authority Confidentiality Advisory Group and London Research 
Ethics Committee (references 5.04(b)/10 and 10/ H0720/18, respectively). Given the anonymous nature of the final dataset, it is not possible to disseminate results to individual study participants; instead results will be shared with fertility practitioners and clinics through the Human Fertility and Embryology Authority networks.

\section{Results \\ Characteristics of study participants}

In total, 255786 women contributed 2257789 person years' follow-up. Average follow-up was 8.8 years (range 1-19 years), with 105436 (41\%) followed for at least 10 years. Average age at first treatment was 34.5 years. Infertility cause involved at least one female factor in 111658 women (44\%; including endometriosis, ovulatory disorders (predominantly polycystic ovary disease), and tubal disease). Infertility was unexplained in 47757 (19\%) women, and was due only to male factors in 84871 (33\%). Average infertility duration was 4.9 years. Women had 1.8 stimulated cycles on average, with only $20 \%$ $(n=50485)$ having more than two stimulated cycles. About half the study population had at least one live birth after treatment completion (table 1).

\section{Breast cancer}

There was no overall increased risk of breast cancer (2578 observed $v 2641.2$ expected cancers; standardised incidence ratio 0.98 (95\% confidence interval 0.94 to 1.01); absolute excess risk -2.8 cases per 100000 person years (95\% confidence interval -7.1 to 1.8 ); table 2). More than three quarters (76\%) of tumours were ductal carcinomas $(n=1963)$, 9\% lobular ( $\mathrm{n}=228), 12 \%$ other epithelial tumours $(n=319)$, and 3\% non-epithelial or unspecified $(n=68)$. There were no significantly raised risks in groups by age at first treatment, infertility duration, number of stimulated cycles, number of live births, and number of multiple births (table 3).

We found significant risk reductions with increasing duration since treatment completion $(\mathrm{P}=0.01$; table 3), and in women with any female factor or only male factor infertility (table 3), but no difference between risks at premenopausal and postmenopausal ages separately (age $<50$ years, standardised incidence ratio 0.98 (95\% confidence interval 0.94 to 1.02 ); $\geq 50$ years, 0.97 ( 0.89 to 1.06 ); data not shown). After exclusion of the first 12 months of follow-up, breast cancer risk was significantly reduced compared with age standardised expectation (standardised incidence ratio 0.95 (0.92 to 0.99$), \mathrm{P}=0.02$; supplementary appendix ). There was no increased risk of invasive breast cancer (standardised incidence ratio 0.96 (0.92 to 1.00); absolute excess risk -4.4 cases per 100000 person years (95\% confidence interval -8.5 to -0.2); table 4), but a small increased risk of in situ breast cancer (291 cancers observed $v 253.5$ cancers

\begin{tabular}{|c|c|c|c|}
\hline Characteristic & Total cohort $(n=255786)$ & $\begin{array}{l}\text { Women who developed ovarian, breast, } \\
\text { and corpus uteri cancer }(n=3155)\end{array}$ & $\begin{array}{l}\text { Women who did not develop ovarian, breast, } \\
\text { and corpus uteri cancer }(n=252631)\end{array}$ \\
\hline Age at first treatment (years; mean (SD)) & $34.5(4.8)$ & $36.3(4.7)$ & $34.5(4.8)$ \\
\hline \multicolumn{4}{|l|}{ Age at first treatment (No (\%)) } \\
\hline$<25$ years & $5671(2)$ & $20(1)$ & $5651(2)$ \\
\hline $25-29$ years & $39932(16)$ & $259(8)$ & $39673(16)$ \\
\hline $30-34$ years & $92788(36)$ & $961(31)$ & $91827(36)$ \\
\hline $35-39$ years & $85868(34)$ & $1244(39)$ & $84624(34)$ \\
\hline 40-44 years & $28174(11)$ & $563(18)$ & $27611(11)$ \\
\hline$\geq 45$ years & $3353(1)$ & $108(3)$ & $3245(1)$ \\
\hline \multicolumn{4}{|l|}{ Cause of infertility (No (\%)) } \\
\hline Any female factor & $111658(44)$ & $1626(52)$ & $110032(44)$ \\
\hline Male factor only & $84871(33)$ & $915(29)$ & $83956(33)$ \\
\hline Unexplained & $47757(19)$ & $474(15)$ & $47283(19)$ \\
\hline Unrecorded & $11500(5)$ & $140(4)$ & $11360(5)$ \\
\hline History of endometriosis (No (\%)) & $18630(7)$ & $281(9)$ & $18349(7)$ \\
\hline History of tubal disease (No (\%)) & $66370(26)$ & $1045(33)$ & $65325(26)$ \\
\hline History of ovulatory disorder (No (\%)) & $36016(14)$ & $451(14)$ & $35565(14)$ \\
\hline $\begin{array}{l}\text { Duration of infertility reported at completion } \\
\text { of last cycle (years; mean (SD)) }\end{array}$ & $4.9(3.3)$ & $5.6(3.9)$ & $4.8(3.3)$ \\
\hline No of stimulated cycles (mean (SD)) & $1.8(1.2)$ & $1.8(1.3)$ & $1.8(1.2)$ \\
\hline $\begin{array}{l}\text { No of live births at completion of last cycle } \\
\text { (mean (SD)) }\end{array}$ & $0.6(0.7)$ & $0.6(0.7)$ & $0.6(0.7)$ \\
\hline \multicolumn{4}{|c|}{ No of live births at completion of last cycle (No (\%)) } \\
\hline 0 & $129217(51)$ & $1775(56)$ & $127442(50)$ \\
\hline 1 & $96839(38)$ & $1011(32)$ & $95828(38)$ \\
\hline$\geq 2$ & $29645(12)$ & $368(12)$ & $29277(11)$ \\
\hline Unrecorded & $85(0)$ & $1(0)$ & $84(0)$ \\
\hline $\begin{array}{l}\text { Any multiple birth recorded at completion of } \\
\text { last cycle (No (\%)) }\end{array}$ & $29366(11)$ & $304(10)$ & $29062(12)$ \\
\hline
\end{tabular}

$\mathrm{SD}=$ standard deviation. 


\begin{tabular}{|c|c|c|c|c|c|}
\hline Type of cancer & $\begin{array}{l}\text { Follow-up (No of } \\
\text { person years) }\end{array}$ & No of observed cancers & No of expected cancers & Standardised incidence ratio $(95 \% \mathrm{Cl})$ & $\begin{array}{l}\text { Absolute excess risk }(95 \% \mathrm{Cl}) \text { per } \\
100000 \text { person years at risk }\end{array}$ \\
\hline \multicolumn{6}{|c|}{ Including first year of follow-up } \\
\hline Breast* $^{\star}$ & 2257789 & 2578 & 2641.2 & 0.98 (0.94 to 1.01$)$ & $-2.8(-7.1$ to 1.8$)$ \\
\hline Corpus uterit & 2257789 & 164 & 146.9 & $1.12(0.95$ to 1.30$)$ & $0.8(-0.3$ to 2.0$)$ \\
\hline Ovary & 2257789 & 405 & 291.82 & 1.39 (1.26 to 1.53$)$ & $5.0(3.3$ to 6.9$)$ \\
\hline \multicolumn{6}{|c|}{ Excluding first year of follow-up } \\
\hline Breast* $^{\star}$ & 2004121 & 2384 & 2501.6 & 0.95 (0.92 to 0.99) & $-5.9(-10.6$ to -1.0$)$ \\
\hline Corpus uterit & 2004121 & 157 & 141.79 & $1.11(0.94$ to 1.30$)$ & $0.8(-0.4$ to 2.1$)$ \\
\hline Ovary & 2004121 & 356 & 271.9 & 1.31 (1.18 to 1.45$)$ & $4.2(2.44$ to 6.10$)$ \\
\hline
\end{tabular}

expected, standardised incidence ratio 1.15 (1.02 to 1.29); absolute excess risk 1.7 cases per 100000 person years (0.2 to 3.2); table 4), which was associated with the number of treatment cycles $(\mathrm{P}=0.03)$. Exclusion of the first 12 months of follow-up did not substantially change results for in situ breast cancer risk (table S5, supplementary appendix).

\section{Carcinoma of the corpus uteri}

Risk of corpus uteri cancer was not significantly raised (standardised incidence ratio 1.12 (95\% confidence interval 0.95 to 1.30); absolute excess risk 0.8 cases per 100000 person years (95\% confidence interval -0.3 to 2.0$)$; table 2$)$. Over $92 \%(n=152)$ of corpus uteri tumours were epithelial, 70\% $(n=107)$ of which were endometrioid; $8 \%$ were non-epithelial or unspecified $(n=12)$. We found a significantly increased risk of corpus uteri cancer in women with an ovulatory disorder (standardised incidence ratio 1.59 (1.13 to 2.17); table 3). There was a highly significant trend of increasing risk with decreased parity $(\mathrm{P}<0.001)$, and a significantly decreased risk with women having a multiple birth (standardised incidence ratio 0.42 (0.14 to 0.99); table 3 ). No significant variation in risk was noted with number of cycles $(\mathrm{P}=0.93)$, age at first treatment $(\mathrm{P}=0.28)$ or duration since treatment completion $(\mathrm{P}=0.12)$. Exclusion of the first 12 months of follow-up did not substantially change results (table S3, supplementary appendix).

\section{Ovarian cancer}

An overall increased risk of ovarian cancer was observed in our study population (standardised incidence ratio 1.39 (95\% confidence interval 1.26 to 1.53); absolute excess risk 5.0 cases per 100000 person years (95\% confidence interval 3.3 to 6.9 ); table 2). Increased risks were seen across most age groups at first treatment, but there was a highly significant trend of increasing risk with decreasing age at first treatment $(\mathrm{P}<0.001$; table 3$)$. Significantly increased risks were found in women who had any diagnosis of female factor infertility (standardised incidence ratio 1.66 (1.46 to 1.88$)$ ), particularly endometriosis (2.31 (1.74 to 3.01$)$ ) or tubal disease (1.68 (1.43 to 1.97); table 3). No increased risk was seen where infertility was male factor only (standardised incidence ratio 1.05 (0.85 to 1.27)) or unexplained (0.96 (0.69 to 1.31); table 3). There was a significant trend of decreasing risk with increasing number of live births $(\mathrm{P}=0.001)$, and women remaining nulliparous after treatment completion conferred the highest risk (standardised incidence ratio 1.57 (1.37 to 1.79); table 3). No increased risk was seen with increasing infertility duration $(\mathrm{P}=0.15)$, number of cycles $(\mathrm{P}=0.86)$, or duration since treatment completion $(\mathrm{P}=0.74)$. Exclusion of the first 12 months of follow-up did not substantially change results (table S3, supplementary appendix).

When tumours were classified as invasive or borderline, significant excesses of both were noted (264 observed $v$ 188.1expected cancers, standardised incidence ratio 1.40 (95\% confidence interval 1.24 to 1.58 ), absolute excess risk 3.4 cases per 100000 person years (95\% confidence interval 2.0 to 4.9 ) and $141 v 103.7,1.36$ ( 1.15 to 1.60$), 1.7$ cases per 100000 person years (0.7 to 2.8 ), respectively; table 4).

\section{Invasive ovarian tumours}

There was a significant trend of increasing risk of invasive ovarian tumours with decreasing age at first treatment $(\mathrm{P}=0.02$; table 4). Significantly increased risks were detected in women who had any diagnosis of female factor infertility (standardised incidence ratio 1.66 (95\% confidence interval 1.41 to 1.94)), particularly endometriosis (2.47 (1.75 to 3.39)) or tubal disease (1.71 (1.40 to 2.08); table 4). Risk significantly decreased with increasing parity $(\mathrm{P}=0.001)$, and women nulliparous after treatment completion were at greatest risk (1.67 (1.42 to 1.95); table 4). We saw no significant variation in risk with number of cycles $(\mathrm{P}=0.29)$, infertility duration $(\mathrm{P}=0.25)$, or duration since treatment completion $(\mathrm{P}=0.44)$, nor was risk raised in women treated for male factor only infertility (1.09 (0.84 to 1.39); table 4). A third of invasive ovarian tumours were serous $(n=87), 25 \%$ endometrioid $(n=66), 8 \%$ mucinous $(n=22), 17 \%$ other or unspecified epithelial tumours $(\mathrm{n}=45)$, and $17 \%$ non-epithelial or unspecified $(\mathrm{n}=44)$. Exclusion of the first 12 months of follow-up did not substantially change results (table S4, supplementary appendix). 
Table 3 | Standardised incidence ratios (SIRs) for ovarian, breast, and corpus uteri cancer among 225786 women who underwent assisted reproduction in Great Britain, 1991-2010, stratified by various factors*

\begin{tabular}{|c|c|c|c|c|c|c|c|}
\hline \multirow[b]{2}{*}{ Factor } & \multirow{2}{*}{$\begin{array}{l}\text { Follow-up } \\
\text { (No of person } \\
\text { years) }\end{array}$} & \multicolumn{2}{|l|}{ Breast cancert } & \multicolumn{2}{|c|}{ Corpus uteri cancer‡ } & \multicolumn{2}{|l|}{ Ovarian cancer§ } \\
\hline & & $\begin{array}{l}\text { No of observed } \\
\text { cancers }\end{array}$ & $\operatorname{SIR}(95 \% \mathrm{Cl})$ & $\begin{array}{l}\text { No of observed } \\
\text { cancers }\end{array}$ & $\operatorname{SIR}(95 \% \mathrm{Cl})$ & $\begin{array}{l}\text { No of observed } \\
\text { cancers }\end{array}$ & SIR $(95 \% \mathrm{Cl})$ \\
\hline \multicolumn{8}{|c|}{ Age at first treatment (years) } \\
\hline$<25$ & 48187 & 14 & 1.32 (0.72 to 2.21$)$ & 0 & $0.00(0.00$ to 6.97$)$ & 6 & 2.21 (0.81 to 4.80$)$ \\
\hline $25-29$ & 381964 & 185 & $0.92(0.79$ to 1.06$)$ & 10 & 1.24 (0.60 to 2.29$)$ & 64 & 2.16 (1.67 to 2.76$)$ \\
\hline 30-34 & 866351 & 774 & 0.95 (0.89 to 1.02$)$ & 43 & 1.19 (0.86 to 1.60$)$ & 142 & $1.52(1.28$ to 1.80$)$ \\
\hline $35-39$ & 714056 & 1033 & 0.97 (0.91 to 1.03$)$ & 72 & $1.22(0.96$ to 1.54$)$ & 134 & $1.23(1.03$ to 1.45$)$ \\
\hline $40-44$ & 218767 & 479 & $1.02(0.93$ to 1.12$)$ & 33 & 0.96 (0.66 to 1.35$)$ & 50 & 1.05 (0.78 to 1.38$)$ \\
\hline$\geq 45$ & 28463 & 93 & 1.09 (0.89 to 1.34$)$ & 6 & $0.68(0.25$ to 1.48$)$ & 9 & $0.97(0.45$ to 1.85$)$ \\
\hline Trend across categories & - & $\mathrm{P}=0.13$ & & $\mathrm{P}=0.28$ & & $P<0.001$ & \\
\hline \multicolumn{8}{|l|}{ Infertility cause } \\
\hline Any female factor & 1109593 & 1279 & 0.95 (0.90 to 1.00$)$ & 97 & $1.25(1.02$ to 1.53$)$ & 246 & 1.66 (1.46 to 1.88$)$ \\
\hline Male factor only & 757063 & 774 & 0.92 (0.86 to 0.99) & 41 & 0.91 (0.65 to 1.24$)$ & 98 & 1.05 (0.85 to 1.27$)$ \\
\hline Unexplained & 326495 & 416 & $1.10(1.00$ to 1.21$)$ & 16 & 0.78 (0.45 to 1.27$)$ & 40 & 0.96 (0.69 to 1.31$)$ \\
\hline Unrecorded & 64638 & 109 & 1.49 (1.24 to 1.80$)$ & 10 & 2.53 (1.21 to 4.66$)$ & 21 & 2.59 (1.60 to 3.95$)$ \\
\hline \multicolumn{8}{|c|}{ History of endometriosis } \\
\hline Yes & 181279 & 214 & 0.98 (0.86 to 1.12$)$ & 9 & $0.75(0.35$ to 1.43$)$ & 55 & 2.31 (1.74 to 3.01$)$ \\
\hline No & 2076509 & 2364 & 0.98 (0.94 to 1.02$)$ & 155 & 1.15 (0.98 to 1.34$)$ & 350 & $1.31(1.17$ to 1.45$)$ \\
\hline \multicolumn{8}{|c|}{ History of tubal disease } \\
\hline Yes & 710522 & 826 & 0.96 (0.90 to 1.03$)$ & 59 & 1.23 (0.93 to 1.58$)$ & 158 & 1.68 (1.43 to 1.97$)$ \\
\hline No & 1547266 & 1752 & 0.98 (0.94 to 1.03$)$ & 105 & 1.06 (0.87 to 1.29$)$ & 247 & $1.25(1.10$ to 1.41$)$ \\
\hline \multicolumn{8}{|c|}{ History of ovulatory problems } \\
\hline Yes & 311523 & 357 & $0.92(0.83$ to 1.02$)$ & 39 & 1.59 (1.13 to 2.17$)$ & 55 & $1.28(0.97$ to 1.67$)$ \\
\hline No & 1946265 & 2221 & $0.99(0.95$ to 1.03$)$ & 125 & $1.02(0.85$ to 1.21$)$ & 350 & $1.41(1.26$ to 1.56$)$ \\
\hline \multicolumn{8}{|c|}{ Duration of infertility at last cycle (years) } \\
\hline$<2$ & 133067 & 171 & $0.95(0.82$ to 1.11$)$ & 6 & $0.55(0.20$ to 1.20$)$ & 28 & 1.44 (0.96 to 2.09) \\
\hline $2-3$ & 439560 & 527 & 1.05 (0.96 to 1.14$)$ & 23 & $0.82(0.52$ to 1.23$)$ & 73 & $1.30(1.02$ to 1.64$)$ \\
\hline $4-5$ & 447739 & 520 & 0.99 (0.90 to 1.07$)$ & 30 & $1.03(0.70$ to 1.47$)$ & 74 & 1.27 (1.00 to 1.60$)$ \\
\hline $6-7$ & 271583 & 316 & 0.91 (0.82 to 1.02) & 27 & 1.38 (0.91 to 2.01) & 60 & 1.61 (1.23 to 2.07$)$ \\
\hline 8-9 & 151580 & 197 & 0.95 (0.83 to 1.10$)$ & 16 & 1.34 (0.77 to 2.18$)$ & 36 & 1.64 (1.15 to 2.27$)$ \\
\hline$\geq 10$ & 209751 & 322 & $0.95(0.85$ to 1.05$)$ & 37 & 1.68 (1.18 to 2.31$)$ & 57 & 1.60 (1.21 to 2.08$)$ \\
\hline Unrecorded & 324953 & 404 & 1.07 (0.97 to 1.18$)$ & 18 & 0.92 (0.54 to 1.45$)$ & 42 & 1.02 (0.74 to 1.38$)$ \\
\hline Trend across categories & - & $P=0.20$ & & $P<0.001$ & & $\mathrm{P}=0.15$ & \\
\hline \multicolumn{8}{|c|}{ Total No of stimulated cycles } \\
\hline 0 (“natural cycle" only) & 90973 & 142 & 0.88 (0.74 to 1.04$)$ & 8 & $0.66(0.28$ to 1.29$)$ & 17 & 0.99 (0.58 to 1.59) \\
\hline 1 & 1041791 & 1203 & 0.98 (0.92 to 1.03$)$ & 89 & 1.29 (1.04 to 1.59$)$ & 196 & $1.44(1.25$ to 1.66$)$ \\
\hline 2 & 473125 & 585 & 1.01 (0.93 to 1.09$)$ & 29 & 0.91 (0.61 to 1.30$)$ & 87 & $1.38(1.10$ to 1.70$)$ \\
\hline $3-4$ & 306137 & 420 & $1.03(0.93$ to 1.13$)$ & 24 & 1.06 (0.68 to 1.58$)$ & 53 & $1.23(0.92$ to 1.60$)$ \\
\hline$\geq 5$ & 66149 & 107 & $1.08(0.89$ to 1.31$)$ & 7 & 1.24 (0.50 to 2.55$)$ & 17 & 1.67 (0.97 to 2.67$)$ \\
\hline Trend across categories & - & $\mathrm{P}=0.07$ & & $\mathrm{P}=0.93$ & & $\mathrm{P}=0.86$ & \\
\hline \multicolumn{8}{|c|}{ Total number of live births at last cycle completion } \\
\hline 0 & 1009134 & 1299 & $0.99(0.93$ to 1.04$)$ & 122 & 1.61 (1.34 to 1.92$)$ & 222 & 1.57 (1.37 to 1.79$)$ \\
\hline 1 & 718998 & 843 & 1.03 (0.96 to 1.10$)$ & 24 & 0.53 (0.34 to 0.79$)$ & 114 & 1.25 (1.03 to 1.50$)$ \\
\hline$\geq 2$ & 249685 & 314 & $0.92(0.82$ to 1.03$)$ & 11 & $0.54(0.27$ to 0.96$)$ & 34 & 0.93 (0.64 to 1.30$)$ \\
\hline Unrecorded & 414 & 1 & $1.82(0.05$ to 10.13$)$ & 0 & $0.00(0.00$ to 99.86$)$ & 0 & 0.00 (0.00 to 49.93) \\
\hline Trend across categories & - & $P=0.56$ & & $P<0.001$ & & $P=0.001$ & \\
\hline \multicolumn{8}{|c|}{ Any multiple birth as recorded at last cycle completion } \\
\hline Yes & 232824 & 258 & $1.10(0.97$ to 1.24$)$ & 5 & $0.42(0.14$ to 0.99$)$ & 33 & $1.23(0.85$ to 1.73$)$ \\
\hline No & 1745409 & 2199 & $0.98(0.94$ to 1.02$)$ & 152 & 1.17 (1.00 to 1.38$)$ & 337 & 1.39 (1.24 to 1.54$)$ \\
\hline \multicolumn{8}{|c|}{ Time since last treatment (years) } \\
\hline $0-3$ & 687180 & 525 & 1.04 (0.95 to 1.13$)$ & 28 & 1.39 (0.92 to 2.00$)$ & 99 & 1.54 (1.25 to 1.88$)$ \\
\hline $3-6$ & 486191 & 529 & 1.04 (0.95 to 1.13$)$ & 29 & $1.28(0.85$ to 1.83$)$ & 73 & 1.27 (1.00 to 1.60$)$ \\
\hline 6-10 & 444324 & 657 & 1.00 (0.93 to 1.08$)$ & 38 & 1.07 (0.76 to 1.47$)$ & 84 & 1.24 (0.99 to 1.53$)$ \\
\hline $10-15$ & 296445 & 590 & 0.93 (0.86 to 1.01$)$ & 45 & 0.99 (0.72 to 1.33$)$ & 86 & 1.39 (1.11 to 1.71$)$ \\
\hline$\geq 15$ & 64091 & 156 & $0.86(0.73$ to 1.01$)$ & 17 & 0.98 (0.57 to 1.57$)$ & 28 & 1.57 (1.05 to 2.27$)$ \\
\hline Trend across categories & - & $P=0.01$ & & $\mathrm{P}=0.12$ & & $\mathrm{P}=0.74$ & \\
\hline
\end{tabular}

*See supplementary appendix for results excluding the first 12 months of follow-up.

tBreast cancer=ICD-9 codes 1740-1749, 2330, and 2383; ICD-10 codes C500-C509, D050-D059, and D486.

‡Corpus uteri cancer=ICD-9 codes $1820-1828$ and ICD-10 code C54.

§Ovarian cancer=ICD-9 codes 1830-1839 and 2362; ICD-10 codes C56, C570-C574, C481, C482, and D391 


\begin{tabular}{|c|c|c|c|c|c|c|c|c|c|}
\hline \multirow[b]{2}{*}{ Factor } & \multirow[b]{2}{*}{$\begin{array}{l}\text { Follow-up } \\
\text { (No of person } \\
\text { years) }\end{array}$} & \multicolumn{2}{|c|}{ Invasive breast cancert } & \multicolumn{2}{|c|}{ In situ breast cancer‡ } & \multicolumn{2}{|c|}{ Invasive ovarian tumours§ } & \multicolumn{2}{|c|}{ Borderline ovarian tumours $\uparrow$} \\
\hline & & $\begin{array}{l}\text { No of } \\
\text { observed } \\
\text { cancers }\end{array}$ & $\operatorname{SIR}(95 \% \mathrm{Cl})$ & $\begin{array}{l}\text { No of } \\
\text { observed } \\
\text { cancers }\end{array}$ & $\operatorname{SIR}(95 \% \mathrm{Cl})$ & $\begin{array}{l}\text { No of } \\
\text { observed } \\
\text { cancers }\end{array}$ & $\operatorname{SIR}(95 \% \mathrm{CI})$ & $\begin{array}{l}\text { No of } \\
\text { observed } \\
\text { cancers }\end{array}$ & $\operatorname{SIR}(95 \% \mathrm{Cl})$ \\
\hline Overall & 2257789 & 2272 & $0.96(0.92$ to 1.00$)$ & 291 & $1.15(1.02$ to 1.29$)$ & 264 & 1.40 (1.24 to 1.58$)$ & 141 & $1.36(1.15$ to 1.60$)$ \\
\hline \multicolumn{10}{|c|}{ Age at first treatment (years) } \\
\hline$<25$ & 48187 & 14 & 1.43 (0.78 to 2.39$)$ & 0 & $0.00(0.00$ to 4.34$)$ & $<5$ & ** & $<5$ & ** \\
\hline $25-29$ & 38964 & 168 & 0.91 (0.78 to 1.06$)$ & 16 & 1.10 (0.63 to 1.78$)$ & 35 & $2.33(1.63$ to 3.25$)$ & 29 & 1.98 (1.33 to 2.85$)$ \\
\hline $30-34$ & 866351 & 685 & 0.92 (0.86 to 1.00$)$ & 85 & $1.27(1.02$ to 1.57$)$ & 81 & $1.46(1.16$ to 1.82$)$ & 61 & 1.61 (1.23 to 2.07$)$ \\
\hline $35-39$ & 714056 & 925 & $0.97(0.91$ to 1.04$)$ & 100 & 0.94 (0.77 to 1.15$)$ & 97 & $1.32(1.07$ to 1.61$)$ & 37 & $1.04(0.73$ to 1.43$)$ \\
\hline $40-44$ & 218767 & 411 & 1.000 .90 to 1.10$)$ & 66 & 1.23 (0.95 to 1.56$)$ & 40 & $1.13(0.80$ to 1.53$)$ & 10 & 0.82 (0.39 to 1.50$)$ \\
\hline$\geq 45$ & 28463 & 69 & 0.94 (0.73 to 1.19$)$ & 24 & $2.12(1.36$ to 3.15$)$ & $<10$ & ** & $<5$ & ** \\
\hline $\begin{array}{l}\text { Trend across } \\
\text { categories }\end{array}$ & - & $P=0.30$ & & $P=0.47$ & & $P=0.02$ & & $P<0.001$ & \\
\hline \multicolumn{10}{|l|}{ Infertility cause } \\
\hline Any female factor & 1109593 & 1118 & 0.92 (0.87 to 0.98$)$ & 151 & 1.14 (0.97 to 1.34$)$ & 161 & $1.66(1.41$ to 1.94$)$ & 85 & 1.66 (1.33 to 2.05$)$ \\
\hline Male factor only & 757063 & 676 & 0.89 (0.83 to 0.96$)$ & 93 & 1.18 (0.95 to 1.44$)$ & 65 & 1.09 (0.84 to 1.39$)$ & 33 & 0.96 (0.66 to 1.35$)$ \\
\hline Unexplained & 326495 & 374 & 1.10 (0.99 to 1.22$)$ & 42 & 1.18 (0.85 to 1.59$)$ & 26 & 0.98 (0.64 to 1.44$)$ & 14 & 0.92 (0.50 to 1.55$)$ \\
\hline Unrecorded & 64638 & 104 & 1.58 (1.30 to 1.92$)$ & 5 & 0.73 (0.24 to 1.70$)$ & 12 & 2.35 (1.21 to 4.10$)$ & 9 & 3.00 (1.37 to 5.70$)$ \\
\hline \multicolumn{10}{|c|}{ History of endometriosis } \\
\hline Yes & 181279 & 186 & 0.95 (0.82 to 1.10$)$ & 26 & 1.25 (0.81 to 1.83 ) & 38 & $2.47(1.75$ to 3.39$)$ & 17 & 2.03 (1.18 to 3.25$)$ \\
\hline No & 2076509 & 2086 & 0.96 (0.92 to 1.00$)$ & 265 & 1.14 (1.01 to 1.28$)$ & 226 & 1.31 (1.14 to 1.49$)$ & 124 & 1.30 (1.08 to 1.55$)$ \\
\hline \multicolumn{10}{|c|}{ History of tubal disease } \\
\hline Yes & 710522 & 725 & $0.94(0.87$ to 1.01$)$ & 92 & 1.11 (0.89 to 1.36$)$ & 105 & $1.71(1.40$ to 2.08$)$ & 53 & $1.62(1.21$ to 2.12$)$ \\
\hline No & 1547266 & 1547 & $0.97(0.92$ to 1.01$)$ & 199 & 1.17 (1.01 to 1.34$)$ & 159 & 1.25 (1.07 to 1.46$)$ & 88 & $1.24(0.99$ to 1.53$)$ \\
\hline \multicolumn{10}{|c|}{ History of ovulatory problems } \\
\hline Yes & 311523 & 315 & 0.91 (0.81 to 1.02$)$ & 41 & 1.05 (0.75 to 1.42$)$ & 33 & $1.16(0.80$ to 1.63$)$ & 22 & 1.52 (0.96 to 2.31$)$ \\
\hline No & 1946265 & 1957 & 0.97 (0.92 to 1.01$)$ & 250 & 1.17 (1.03 to 1.32$)$ & 231 & 1.45 (1.27 to 1.65$)$ & 119 & 1.33 (1.11 to 1.60$)$ \\
\hline \multicolumn{10}{|c|}{ Duration of infertility at last cycle (years) } \\
\hline$<2$ & 133067 & 156 & 0.97 (0.83 to 1.14$)$ & 15 & 0.82 (0.46 to 1.35$)$ & 16 & 1.23 (0.70 to 1.99$)$ & 12 & 1.89 (0.98 to 3.30) \\
\hline $2-3$ & 439560 & 464 & 1.03 (0.94 to 1.13$)$ & 61 & 1.26 (0.97 to 1.62$)$ & 53 & 1.48 (1.11 to 1.93$)$ & 20 & 0.99 (0.61 to 1.53 ) \\
\hline 4-5 & 447739 & 461 & $0.97(0.89$ to 1.07$)$ & 52 & 1.03 (0.77 to 1.35$)$ & 53 & $1.42(1.06$ to 1.85$)$ & 21 & $1.02(0.63$ to 1.55$)$ \\
\hline $6-7$ & 271583 & 278 & 0.90 (0.79 to 1.01$)$ & 35 & 1.03 (0.72 to 1.44$)$ & 40 & 1.63 (1.16 to 2.21$)$ & 20 & 1.57 (0.96 to 2.42$)$ \\
\hline $8-9$ & 151580 & 169 & 0.92 (0.78 to 1.06$)$ & 27 & 1.31 (0.86 to 1.91$)$ & 27 & 1.84 (1.21 to 2.67$)$ & 9 & 1.24 (0.57 to 2.36$)$ \\
\hline$\geq 10$ & 209751 & 279 & $0.92(0.82$ to 1.04$)$ & 42 & 1.15 (0.83 to 1.56$)$ & 40 & 1.60 (1.14 to 2.18$)$ & 17 & 1.61 (0.94 to 2.58 ) \\
\hline Unrecorded & 324953 & 355 & 1.05 (0.94 to 1.16$)$ & 48 & 1.37 (1.01 to 1.82 ) & 25 & 0.97 (0.63 to 1.43$)$ & 17 & 1.12 (0.65 to 1.79$)$ \\
\hline Trend across & - & $P=0.11$ & & $P=0.58$ & & $P=0.25$ & & $P=0.42$ & \\
\hline
\end{tabular}

categories

Total number of stimulated cycles

\begin{tabular}{llllllllll}
\hline $\begin{array}{c}\text { o ("natural cycle" } \\
\text { only) }\end{array}$ & 90973 & 121 & $0.85(0.71$ to 1.02$)$ & 21 & $1.14(0.71$ to 1.74$)$ & 13 & $1.04(0.55$ to 1.78$)$ & $<5$ \\
\hline 1 & 1041791 & 1073 & $0.97(0.91$ to 1.03$)$ & 121 & $1.02(0.85$ to 1.22$)$ & 129 & $1.47(1.23$ to 1.75$)$ & 67 & $1.39(1.08$ to 1.77$)$ \\
\hline 2 & 473125 & 512 & $0.98(0.90$ to 1.07$)$ & 70 & $1.25(0.97$ to 1.58$)$ & 56 & $1.37(1.03$ to 1.78$)$ & 31 & $1.40(0.95$ to 1.98$)$ \\
\hline $3-4$ & 306137 & 371 & $1.01(0.92$ to 1.12$)$ & 47 & $1.18(0.87$ to 1.57$)$ & 42 & $1.48(1.06$ to 1.99$)$ & 11 & $0.75(0.37$ to 1.33$)$ \\
\hline$\geq 5$ & 66149 & 85 & $0.96(0.77$ to 1.91$)$ & 21 & $2.11(1.31$ to 3.23$)$ & 14 & $2.04(1.11$ to 3.42$)$ & $<5$ & $* *$ \\
\hline Trend across & - & $\mathrm{P}=0.27$ & & $\mathrm{P}=0.03$ & & $\mathrm{P}=0.29$ & & $\mathrm{P}=0.18$ &
\end{tabular}

categories

Total number of live births after last treatment

\begin{tabular}{|c|c|c|c|c|c|c|c|c|c|}
\hline 0 & 1009134 & 1154 & $0.98(0.92$ to 1.04$)$ & 135 & 1.04 (0.87 to 1.23$)$ & 156 & $1.67(1.42$ to 1.95$)$ & 66 & $1.38(1.07$ to 1.75$)$ \\
\hline 1 & 718998 & 732 & 0.99 (0.92 to 1.07$)$ & 107 & $1.37(1.12$ to 1.65$)$ & 78 & $1.34(1.06$ to 1.67$)$ & 36 & $1.09(0.76$ to 1.51$)$ \\
\hline$\geq 2$ & 249685 & 276 & 0.90 (0.80 to 1.02$)$ & 37 & 1.07 (0.76 to 1.48$)$ & 20 & 0.81 (0.50 to 1.26$)$ & 14 & $1.16(0.63$ to 1.95$)$ \\
\hline Unrecorded & 414 & 0 & 0.00 & 1 & $\begin{array}{l}20.00 \text { (0.51 to } \\
111.43)\end{array}$ & 0 & $\begin{array}{l}0.00(0.00 \text { to } \\
74.89)\end{array}$ & 0 & 0.0 (0.0 to 149.79$)$ \\
\hline $\begin{array}{l}\text { Trend across } \\
\text { categories }\end{array}$ & - & $P=0.37$ & & $P=0.32$ & & $P=0.001$ & & $P=0.34$ & \\
\hline \multicolumn{10}{|c|}{ Any multiple birth recorded } \\
\hline Yes & 232824 & 234 & 1.10 (0.97 to 1.25$)$ & 22 & 1.05 (0.66 to 1.58$)$ & 22 & 1.34 (0.84 to 2.03 ) & 11 & 1.06 (0.53 to 1.90$)$ \\
\hline No & 1745409 & 1928 & 0.96 (0.92 to 1.00$)$ & 258 & $1.16(1.02$ to 1.31$)$ & 232 & $1.45(1.27$ to 1.65$)$ & 105 & 1.27 (1.04 to 1.54$)$ \\
\hline \multicolumn{10}{|c|}{ Time since last treatment (years) } \\
\hline $0-3$ & 687180 & 488 & 1.05 (0.96 to 1.15$)$ & 37 & $1.06(0.71$ to 1.39$)$ & 62 & $1.73(1.33$ to 2.22$)$ & 37 & $1.30(0.92$ to 1.79$)$ \\
\hline $3-6$ & 486191 & 476 & 1.03 (0.94 to 1.12$)$ & 51 & $1.24(0.93$ to 1.63$)$ & 45 & $1.27(0.93$ to 1.71$)$ & 28 & 1.27 (0.85 to 1.84$)$ \\
\hline $6-10$ & 444324 & 556 & 0.94 (0.87 to 1.02$)$ & 95 & $1.52(1.23$ to 1.85$)$ & 63 & $1.37(1.05$ to 1.75$)$ & 21 & $0.96(0.59$ to 1.46$)$ \\
\hline
\end{tabular}




\begin{tabular}{|c|c|c|c|c|c|c|c|c|c|}
\hline \multirow[b]{2}{*}{ Factor } & \multirow[b]{2}{*}{$\begin{array}{l}\text { Follow-up } \\
\text { (No of person } \\
\text { years) }\end{array}$} & \multicolumn{2}{|c|}{ Invasive breast cancert } & \multicolumn{2}{|c|}{ In situ breast cancerf } & \multicolumn{2}{|c|}{ Invasive ovarian tumours§ } & \multicolumn{2}{|c|}{ Borderline ovarian tumours } \\
\hline & & $\begin{array}{l}\text { No of } \\
\text { observed } \\
\text { cancers }\end{array}$ & $\operatorname{SIR}(95 \% \mathrm{CI})$ & $\begin{array}{l}\text { No of } \\
\text { observed } \\
\text { cancers }\end{array}$ & SIR $(95 \% \mathrm{CI})$ & $\begin{array}{l}\text { No of } \\
\text { observed } \\
\text { cancers }\end{array}$ & $\operatorname{SIR}(95 \% \mathrm{CI})$ & $\begin{array}{l}\text { No of } \\
\text { observed } \\
\text { cancers }\end{array}$ & SIR $(95 \% \mathrm{CI})$ \\
\hline$\geq 10$ & 296445 & 510 & $0.93(0.85$ to 1.01$)$ & 75 & $0.98(0.77$ to 1.22$)$ & 63 & 1.38 (1.06 to 1.77$)$ & 23 & 1.39 (0.88 to 2.08$)$ \\
\hline$\geq 15$ & 64091 & 132 & $0.86(0.72$ to 1.02$)$ & 22 & 0.85 (0.54 to 1.29$)$ & 21 & 1.52 (0.94 to 2.32$)$ & 7 & $1.75(0.70$ to 3.60$)$ \\
\hline Trend across & - & $P=0.005$ & & $P=0.29$ & & $P=0.44$ & & $P=0.84$ & \\
\hline
\end{tabular}

categories

*See supplementary appendix for results excluding the first 12 months of follow-up.

tInvasive breast cancer=ICD-9 codes 1740-1749 and ICD-10 codes C500-C509.

¥In situ breast cancer=ICD-9 code 2330 and ICD-10 code D050-D059.

§Invasive ovarian tumours=ICD-9 codes 1830-1839 (excluding morphology codes 8442/8451/8462/8472/8473) and 2362; ICD-10 codes C56, C570-C574, C481, and C482 (excluding

morphology codes 8442/8451/8462/8472/8473).

१Borderline ovarian tumours=ICD-9 code 1830 (with morphology codes 8442/8451/8462/8472/8473) and ICD-10 codes D391 and C56 (with morphology codes

$8442 / 8451 / 8462 / 8472 / 8473)$

${ }^{\star *}$ Data suppressed to comply with data disclosure regulations where cells relate to small numbers of individuals. None of the standardised incidence ratios for affected cells approached

significance.

\section{Borderline ovarian tumours}

Significantly increased risks of borderline ovarian tumour was associated with decreasing age at first treatment $(\mathrm{P}<0.001)$ and any diagnosis of female factor infertility (standardised incidence ratio 1.66 (95\% confidence interval 1.33 to 2.05$)$ ), particularly endometriosis (2.03 (1.18 to 3.25)) or tubal disease (1.62 (1.21 to 2.12); table 4). Risk did not change significantly with number of cycles $(\mathrm{P}=0.18)$, parity $(\mathrm{P}=0.34)$, infertility duration $(\mathrm{P}=0.42)$, or duration since treatment completion $(\mathrm{P}=0.84)$, nor was risk raised in women treated for male factor only infertility (0.96 (0.66 to 1.35); table 4). Close to half of borderline tumours were serous $(n=64), 34 \%$ mucinous $(n=48)$, less than $2 \%$ endometrioid $(n<5)$, less than $2 \%$ other or unspecified epithelial tumours $(n<5)$, and $18 \%$ non-epithelial or unspecified $(n=25)$. Exclusion of the first 12 months of follow-up reduced the risk of borderline ovarian tumours (1.19 (0.98 to 1.43); table $S 4$, supplementary appendix) and risk in relation to endometriosis (1.57 (0.81 to 2.73); table S4, supplementary appendix).

\section{Ovarian cancer risk stratified by risk factors}

Parous women who did not have a diagnosis of endometriosis did not have an increased risk of ovarian cancer overall (standardised incidence ratio 1.03 (95\% confidence interval 0.86 to 1.22$)$ ), invasive tumours (1.03 (0.82 to 1.27$)$ ), or borderline tumours (1.02 (0.75 to 1.35 ); table 5). Risks of all types of ovarian cancer were raised in nulliparous women who did not have a diagnosis of endometriosis but to a lesser extent than in parous women with endometriosis (table 5). Women who were nulliparous with a diagnosis of endometriosis had greater risk of invasive ovarian tumour (2.64 (1.69 to 3.93); table 5) than women with just one of these risk factors. By contrast, nulliparous women with endometriosis had no significant risk of a borderline tumour (1.47 (0.59 to 3.04)), although nulliparity and endometriosis were each separately associated with increased risk (table 5). The significant association between decreasing age at first treatment and increasing risk of invasive ovarian tumour was present in women with at least one of endometriosis or nulliparity $(\mathrm{P}<0.001)$, but not in those without either

\begin{tabular}{|c|c|c|c|c|c|c|c|}
\hline \multirow[b]{3}{*}{ Factor } & \multirow[b]{3}{*}{$\begin{array}{l}\text { Follow-up (No of } \\
\text { person years) }\end{array}$} & \multicolumn{6}{|c|}{ Type of ovarian cancer } \\
\hline & & \multicolumn{2}{|c|}{ All ovarian cancer* } & \multicolumn{2}{|l|}{ Invasive cancert } & \multicolumn{2}{|c|}{ Borderline tumours $¥$} \\
\hline & & $\begin{array}{l}\text { No of observed } \\
\text { cancers }\end{array}$ & $\operatorname{SIR}(95 \% \mathrm{Cl})$ & $\begin{array}{l}\text { No of observed } \\
\text { cancers }\end{array}$ & $\operatorname{SIR}(95 \% \mathrm{Cl})$ & $\begin{array}{l}\text { No of observed } \\
\text { cancers }\end{array}$ & SIR $(95 \% \mathrm{Cl})$ \\
\hline $\begin{array}{l}\text { No diagnosis of endometriosis } \\
\text { and at least one birth recorded } \\
\text { by treatment completion }\end{array}$ & 1036996 & 133 & 1.03 (0.86 to 1.22 ) & 85 & 1.03 (0.82 to 1.27$)$ & 48 & 1.02 (0.75 to 1.35$)$ \\
\hline $\begin{array}{l}\text { No diagnosis of endometriosis } \\
\text { and no births recorded by } \\
\text { treatment completion }\end{array}$ & 1039514 & 217 & 1.57 (1.37 to 1.79$)$ & 141 & 1.56 (1.32 to 1.84$)$ & 76 & 1.57 (1.24 to 1.97$)$ \\
\hline $\begin{array}{l}\text { Diagnosis of endometriosis and } \\
\text { at least one birth recorded by } \\
\text { treatment completion }\end{array}$ & 79870 & 24 & 2.41 (1.55 to 3.59$)$ & 14 & 2.22 (1.21 to 3.72$)$ & 10 & 2.76 (1.33 to 5.08$)$ \\
\hline $\begin{array}{l}\text { Diagnosis of endometriosis and } \\
\text { no birth recorded by treatment }\end{array}$ & 101368 & 31 & 2.24 (1.52 to 3.18$)$ & 24 & 2.64 (1.69 to 3.93$)$ & 7 & 1.47 (0.59 to 3.04$)$ \\
\hline
\end{tabular}

completion

*Ovarian cancer=ICD-9 codes 1830-1839 and 2362; ICD-10 codes C56, C570-C574, C481, C482, and D391.

tInvasive ovarian tumours=ICD-9 codes 1830-1839 (excluding morphology codes 8442/8451/8462/8472/8473) and 2362; ICD-10 codes C56, C570-C574, C481, and C482 (excluding morphology codes 8442/8451/8462/8472/8473).

‡Borderline ovarian tumours=ICD-9 code 1830 (with morphology codes 8442/8451/8462/8472/8473) and ICD-10 codes D391 and C56 (with morphology codes

$8442 / 8451 / 8462 / 8472 / 8473)$. 
$(\mathrm{P}=0.62)$; however, these analyses were based on small numbers (table S6, supplementary appendix).

\section{Discussion}

Assisted reproduction is practiced worldwide, and more than five million children have been born as a result. $^{28}$ It is important to establish related disease risks for affected individuals, public health systems, and for counselling of potential patients. In this large population based cohort, we found no overall increased risk of breast cancer associated with assisted reproduction, consistent with most ${ }^{3-10}$ but not all ${ }^{12}$ published studies. We found no significant association between the risk of breast cancer and age at first treatment, in contrast to a small number of earlier studies. ${ }^{8929}$ Reasons for significant decreases in breast cancer risk seen in some subanalyses-such as women who had assisted reproduction for female factor infertility-are unclear, but could reflect beneficial levels of lifestyle related risk factors for breast cancer. ${ }^{30}$

${ }^{31}$ However, details of these risk factors and also age at first birth were not available.

Menopausal status did not seem to account for the significant reduction in risk with increasing follow-up. Despite no increased risk of invasive breast tumours, there was a significant increase in in situ tumours which was significantly associated with increasing number of stimulated cycles. Interpretation of these findings is challenging: the significant association with increasing number of cycles suggests a causal association, yet there was no overall increased risk of breast cancer. Other potential explanations include surveillance bias, chance, and potential confounding by factors such as socioeconomic status, given that most cycles within our cohort were privately funded. To our knowledge, this study is the first to analyse risks of in situ and invasive breast cancers after assisted reproduction separately, so there are no previous data with which to compare.

Risk of corpus uteri cancer overall was not raised in our study. Women with the known risk factor of nulliparity $^{32}$ and those with a history of ovulatory problems (mainly the known risk factor polycystic ovary disease ${ }^{33}$ ) were found to have an increased risk of corpus uteri cancer. Most similar studies contained few events. ${ }^{356}$ The largest studies included $15^{4}$ and 49 cases $^{7}$ of endometrial cancer in women after assisted reproduction, and neither suggested an increased risk.

We found an excess of ovarian cancer compared with age standardised expectation. Significant increases were observed for both invasive and borderline tumours, but were not seen in women without the known risk factors of endometriosis ${ }^{3435}$ and nulliparity. ${ }^{35}$ Ovarian cancer risks were not associated with number of treatment cycles, time since treatment completion, or male factor or unexplained infertility, which argues against a causal role for assisted reproduction procedures. However, we did find a significant association between age at first treatment and risk of all, invasive, and borderline ovarian cancers. Previous studies investigating invasive ovarian tumour risk after assisted reproduction ${ }^{3-711} 131516$ have generally found increased risks in comparison with the general population when potential confounding effects of infertility have not been considered, ${ }^{16}$ but not when such factors were taken into account. ${ }^{3411}$ While our study compared cancer incidence with that in the general population (standardised for age and calendar year), it had sufficient size to stratify by potential confounding factors and thereby to investigate characteristics of associations. We found an increased risk of borderline ovarian tumour in women having assisted reproduction compared with the general population. As with invasive ovarian tumours, this increased risk was not seen in parous women without endometriosis. Few studies have investigated the risk of borderline ovarian cancer in women after assisted reproduction, ${ }^{6} 1314$ but increased risks have been found in studies in the Netherlands ${ }^{13}$ and Australia. ${ }^{14}$

Although the increased risk in borderline ovarian cancer in women with assisted reproduction could be genuine, it could also be due to surveillance bias. The frequency of borderline tumour diagnosis is increased in ovarian cancer screening studies using ultrasound, ${ }^{36}$ and women who have undergone assisted reproduction might have more frequent ultrasound scans after treatment than the general population. This potential bias is supported by the reduction in overall risk after we excluded the first 12 months of followup. However, sensitivity analyses looking at time to diagnosis, age at diagnosis, diagnosis in women of high socioeconomic status, and clinical presentation in other studies suggested surveillance bias an unlikely cause of increased risks. ${ }^{1314}$ We are not able to further differentiate surveillance bias from a genuine increase in borderline tumours. Women with unrecorded cause of infertility had significantly increased rates of breast, ovarian, and corpus uteri cancers. Reasons are unclear but might include reverse causality (box S2, supplementary appendix).

\section{Strengths and limitations of the study}

Most studies investigating risks of cancer in women after assisted reproduction have been small, ${ }^{6}$ with few events and short follow-up. ${ }^{4-7}$ Two of the largest studies published so far include $67608^{4}$ and $113226^{7}$ women treated with assisted reproduction. Systematic reviews have included at most 70753 treated women for analyses of breast cancer risk, ${ }^{10} 79143$ for ovarian cancer risk, ${ }^{16}$ and 118320 for analysis of all gynaecological cancer risk. ${ }^{37}$ Our study comprised over 250000 treated women, including almost 65000 person years of follow-up for at least 15 years beyond last treatment with an average follow-up of 8.8 years and a maximum follow-up of 19 years (table S2, supplementary appendix). However, we cannot exclude the possibility of different risk profiles for any studied cancer on longer follow-up, at ages when most reproductive related cancers occur. ${ }^{35}$

Women treated with assisted reproduction are likely to differ from the general population in their parity, age at first birth, age at menopause, and 
the incidence of predisposing conditions such as endometriosis. More information on these and other factors (eg, socioeconomic status, oral contraceptive use, body mass index, and breastfeeding) would be useful. Comparison to women with untreated infertility problems might have been beneficial, although interpretational problems would remain because of potential selection factors for treatment. Although our study was not able to compare with such a group as some smaller studies have done, ${ }^{4}$ 1314 large study size enabled us to stratify for some important potential confounders and draw inferences despite using general population rates as our comparator. While comparator rates do include cohort participants, less than $5 \%$ of the population of reproductive age women underwent assisted reproduction, and our standardised incidence ratios were generally lower than 2.0; therefore, resulting bias will have been minimal. ${ }^{38}$

Infertility diagnoses were reported by treating fertility clinics to the HFEA. No data were available about how such diagnoses were made. Further details of specific treatments could have enabled detailed analysis of risk by treatment type. However, over our 19 year study period, ovarian stimulation regimens as part of assisted reproductive cycles have been relatively constant, with the majority of advances leading to better success rates having occurred in assisted reproduction laboratories. Gonadotrophin injections have been used for ovarian stimulation and human chorionic gonadotropin for triggering ovulation throughout the study period, and while new highly purified and recombinant versions have been used in more recent years, they are essentially equivalent. Clomifene citrate was used as additional ovarian stimulation in the pioneering years of assisted reproduction treatment, but this was uncommon by 1991. Downregulated cycles using GnRH (gonadotrophin releasing hormone) agonists were standard by 1991 and not replaced by GnRH antagonists as standard until after the study period. Progesterone support was used throughout the study period. The number of ovarian punctures per cycle and information about fertility treatment before assisted reproduction were not available.

\section{Conclusions and implications}

In this large, national population based study of British women after assisted reproductive technology treatment, no increased risk of corpus uteri or invasive breast cancer was detected. There was an increased risk of in situ breast cancer associated with increasing number of treatment cycles. We also observed an excess of all types of ovarian cancer. However, our results suggest that this finding is more likely due to underlying patient characteristics, rather than assisted reproduction itself. We were not able to distinguish between a genuine increase in risk of borderline ovarian tumours and other explanations including surveillance bias. Further investigation of this and longer follow-up is warranted to continue monitoring these important outcomes in this ever growing population.
We thank the Human Fertilisation and Embryology Authority for access to their original dataset and advice on data governance, and the National Health Service Digital and National Records for Scotland for their roles in the data linkage process and access to cancer registration data.

Contributors: CLW jointly conceptualised and designed the study, devised the linkage protocol, supervised the linkage, carried out the analysis, interpreted data, drafted the initial manuscript, and approved the final manuscript as submitted. MEJ jointly conceptualised and designed the study, jointly supervised the analysis, interpreted data, reviewed and revised the manuscript, and approved the final manuscript as submitted. AJS jointly conceptualised and designed the study, interpreted data, reviewed and revised the manuscript, and approved the final manuscript as submitted. BJB jointly conceptualised and designed the study, jointly supervised the analysis, interpreted data, reviewed and revised the manuscript, and approved the final manuscript as submitted. MCD jointly conceptualised and designed the study, interpreted data, reviewed and revised the manuscript, and approved the final manuscript as submitted. IJ jointly conceptualised and designed the study, interpreted data, reviewed and revised the manuscript, and approved the final manuscript as submitted. KJB jointly conceptualised and designed the study, interpreted data, reviewed and revised the manuscript, and approved the final manuscript as submitted. MFGM jointly conceptualised and designed the study, interpreted data, reviewed and revised the manuscript, and approved the final manuscript as submitted. AGS jointly conceptualised and designed the study, interpreted data, reviewed and revised the manuscript, and had the final decision over submission of the approved the final manuscript. All authors had access to the data and take responsibility for the integrity of the data and accuracy of the data analysis. The corresponding author attests that all listed authors meet authorship criteria and that no others meeting the criteria have been omitted. AGS acts as guarantor for this study.

Funding: This research was funded by Cancer Research UK (11704) and the National Institute for Health Research (NIHR; 405526 to CLW), and supported by the NIHR Biomedical Research Centre at Great Ormond Street Hospital for Children NHS Foundation Trust and University College London. This paper presents independent research funded by the NIHR. The views expressed are those of the authors and not necessarily those of the NHS, the NIHR or the Department of Health and Social Care. II is funded by Breast Cancer Now. The Institute of Cancer Research acknowledges NHS funding to the Royal Marsden/ICR NIHR Biomedical Research Centre. AGS's research on this project is partly funded by Medical Research Council grant number MR/L020335/1. No funders or sponsors had any role in the study design, data collection, analysis, interpretation of data and decision to submit for publication. All researchers are independent from funders and sponsors.

Competing interests: All authors have completed the ICMJE uniform disclosure form at www.icmje.org/coi_disclosure.pdf and declare: support for this study from Cancer Research UK and NIHR; $\mathrm{MEJ}$ additionally received funding from Breast Cancer Now, and KJB and MFGM received funding from the UK Department of Health and Children with Cancer UK during the study; IJ reports personal fees from Abcodia and Women's Health Specialists, and receives royalties as coinventor of the ROCA algorithm; MCD reports personal fees from the Centre for Reproductive and Genetic Health; the authors declare no other relationships or activities that could appear to have influenced the submitted work.

Ethical approval: Approval of the study and waiver of the requirement for individual consent were obtained from the UK Health Research Authority Confidentiality Advisory Group and London Research Ethics Committee (references 5.04(b)/10 and 10/ H0720/18, respectively).

Data sharing: No additional data are available, in compliance with ethical and governance regulations under which this research was undertaken.

AGS affirms that the manuscript is an honest, accurate, and transparent account of the study being reported; that no important aspects of the study have been omitted; and that any discrepancies from the study as planned (and, if relevant, registered) have been explained.

This is an Open Access article distributed in accordance with the terms of the Creative Commons Attribution (CC BY 4.0) license, which permits others to distribute, remix, adapt and build upon this work, for commercial use, provided the original work is properly cited. See: http://creativecommons.org/licenses/by/4.0/. 
1 Fathalla MF. Incessant ovulation-a factor in ovarian neoplasia? Lancet 1971:2:163. doi:10.1016/S0140-6736(71)92335-X

2 Henderson BE, Ross R, Bernstein L. Estrogens as a cause of human cancer: the Richard and Hinda Rosenthal Foundation award lecture. Cancer Res 1988;48:246-53.

3 Venn A, Watson L, Bruinsma F, Giles G, Healy D. Risk of cancer after use of fertility drugs with in-vitro fertilisation. Lancet 1999;354:1586-90. doi:10.1016/S0140-6736(99)05203-4

4 Brinton LA, Trabert B, Shalev V, Lunenfeld E, Sella T, Chodick G. In vitro fertilization and risk of breast and gynecologic cancers: a retrospective cohort study within the Israeli Maccabi Healthcare Services. Fertil Steril 2013;99:1189-96. doi:10.1016/j. fertnstert.2012.12.029

5 Källén B, Finnström O, Lindam A, Nilsson E, Nygren KG, Olausson PO Malignancies among women who gave birth after in vitro fertilization. Hum Reprod 2011;26:253-8. doi:10.1093/humrep/deq307

6 Yli-Kuha AN, Gissler M, Klemetti R, Luoto R, Hemminki E. Cancer morbidity in a cohort of 9175 Finnish women treated for infertility. Hum Reprod 2012;27:1149-55. doi:10.1093/humrep/des031

7 Luke B, Brown MB, Spector LG, et al. Cancer in women after assisted reproductive technology. Fertil Steril 2015;104:1218-26. doi:10.1016/j.fertnstert.2015.07.1135

8 Pappo I, Lerner-Geva L, Halevy A, et al. The possible association between IVF and breast cancer incidence. Ann Surg Oncol 2008;15:1048-55. doi:10.1245/s10434-007-9800-2

9 Sergentanis TN, Diamantaras AA, Perlepe C, Kanavidis P, Skalkidou A, Petridou ET. IVF and breast cancer: a systematic review and meta-analysis. Hum Reprod Update 2014;20:106-23. doi:10.1093/ humupd/dmt034

10 Gennari A, Costa M, Puntoni M, et al. Breast cancer incidence after hormonal treatments for infertility: systematic review and meta-analysis of population-based studies. Breast Cancer Res Treat 2015:150:405-13. doi:10.1007/s10549-015-3328-0

11 Rizzuto I, Behrens RF, Smith LA. Risk of ovarian cancer in women treated with ovarian stimulating drugs for infertility. Cochrane Database Syst Rev 2013;8:CD008215.

12 Reigstad MM, Larsen IK, Myklebust TA, et al. Risk of breast cancer following fertility treatment--a registry based cohort study of parous women in Norway. Int J Cancer 2015;136:1140-8. doi:10.1002/ ijc. 29069

13 van Leeuwen FE, Klip H, Mooij TM, et al. Risk of borderline and invasive ovarian tumours after ovarian stimulation for in vitro fertilization in a large Dutch cohort. Hum Reprod 2011;26:3456-65. doi:10.1093/humrep/der322

14 Stewart LM, Holman CD, Finn JC, Preen DB, Hart R. In vitro fertilization is associated with an increased risk of borderline ovarian tumours. Gynecol Oncol 2013;129:372-6. doi:10.1016/j.ygyno.2013.01.027

15 Stewart LM, Holman CD, Aboagye-Sarfo P, Finn JC, Preen DB, Hart R. In vitro fertilization, endometriosis, nulliparity and ovarian cancer risk. Gynecol Oncol 2013;128:260-4. doi:10.1016/j.ygyno.2012.10.023

16 Siristatidis C, Sergentanis TN, Kanavidis P, et al. Controlled ovarian hyperstimulation for IVF: impact on ovarian, endometrial and cervical cancer--a systematic review and meta-analysis. Hum Reprod Update 2013;19:105-23. doi:10.1093/humupd/dms051

17 Reigstad MM, Storeng R, Myklebust TA, et al. Cancer risk in women treated with fertility drugs according to parity status-a registry-based cohort study. Cancer Epidemiol Biomarkers Prev 2017;26:953-62. doi:10.1158/1055-9965.EPI-16-0809

18 Dor J, Lerner-Geva L, Rabinovici J, et al. Cancer incidence in a cohort of infertile women who underwent in vitro fertilization. Fertil Steril 2002;77:324-7. doi:10.1016/S0015-0282(01)02986-7

19 Jensen A, Sharif H, Kjaer SK. Use of fertility drugs and risk of uterine cancer: results from a large Danish population-based cohort study. Am J Epidemiol 2009;170:1408-14. doi:10.1093/aje/kwp290

20 Rossing MA, Daling JR, Weiss NS, Moore DE, Self SG. Ovarian tumors in a cohort of infertile women. N Engl / Med 1994:331:771-6. doi:10.1056/NEIM199409223311204

21 Jensen A, Sharif H, Frederiksen K, Kjaer SK. Use of fertility drugs and risk of ovarian cancer: Danish Population Based Cohort Study. BMJ 2009;338:b249. doi:10.1136/bmj.b249
22 Zegers-Hochschild F, Adamson GD, Dyer S, et al. The International Glossary on Infertility and Fertility Care, 2017. Fertil Steril 2017;108:393-406. doi:10.1016/j. fertnstert.2017.06.005

23 Scotland ISD. Scottish Cancer Registry: NHS National Services Scotland; 2010 [Available from: http://www.isdscotland.org/HealthTopics/Cancer/Scottish-Cancer-Registry.asp

24 Statistics OfN. Cancer Registrations, 1971 to 2011: Office for National Statistics; 2014 [updated 19th June 2014. Available from: http://www.ons.gov.uk/ons/rel/vsob1/cancer-statistics-registrationsengland-series-mb1-/no-43-2012/stb-cancer-registrations-2012. html\#tab-Cancer-registrations-1971-to-2011.

25 Parkin DMCV, Ferlay J, Galceran J, Storm HH, Whelan SL. Comparability and Quality Control in Cancer Registration. Lyon: International Agency for Research on Cancer; 1994. Contract No: technical report No 19.

26 Breslow NE, Day NE. Statistical Methods in Cancer Research. International Agency for Research on Cancer, 1987, Available from http://www.iarc.fr/en/publications/pdfs-online/ stat/sp82/.

27 Stata Corp. Stata Statistical Software: Release 12. Stata Corp LP, 2013.

28 Adamson GD, Tabangin M, Macaluso M, de Mouzon J. The number of babies born globally after treatment with the assisted reproductive technologies (ART). Fertil Steril 2013;100:S42-S. doi:10.1016/j. fertnstert.2013.07.1807.

29 Stewart LM, Holman CD, Hart R, Bulsara MK, Preen DB, Finn JC. In vitro fertilization and breast cancer: is there cause for concern? Fertil Steril 2012;98:334-40. doi:10.1016/j. fertnstert.2012.04.019

30 Domar AD, Conboy L, Denardo-Roney J, Rooney KL. Lifestyle behaviors in women undergoing in vitro fertilization: a prospective study. Fertil Steril 2012;97:697-701.e1. doi:10.1016/j. fertnstert.2011.12.012

31 Key TJ, Verkasalo PK, Banks E. Epidemiology of breast cancer. Lancet Oncol 2001;2:133-40. doi:10.1016/S1470-2045(00)00254-0

32 Cetin I, Cozzi V, Antonazzo P. Infertility as a cancer risk factor - a review. Placenta 2008;29(Suppl B):169-77. doi:10.1016/j. placenta.2008.08.007

33 Barry JA, Azizia MM, Hardiman PJ. Risk of endometrial, ovarian and breast cancer in women with polycystic ovary syndrome: a systematic review and meta-analysis. Hum Reprod Update 2014;20:748-58. doi:10.1093/humupd/dmu012

34 Wentzensen N, Poole EM, Trabert B, et al. Ovarian Cancer Risk Factors by Histologic Subtype: An Analysis From the Ovarian Cancer Cohort Consortium. / Clin Oncol 2016;34:2888-98. doi:10.1200/ ICO.2016.66.8178

35 Ovarian Cancer Research Fund Alliance (OCRFA). Ovarian Cancer Statisticshttps://ocrfa.org/patients/about-ovarian-cancer/ statistics/2016/.

36 Menon U, Gentry-Maharaj A, Hallett R, et al. Sensitivity and specificity of multimodal and ultrasound screening for ovarian cancer, and stage distribution of detected cancers: results of the prevalence screen of the UK Collaborative Trial of Ovarian Cancer Screening (UKCTOCS). Lancet Oncol 2009;10:327-40. doi:10.1016/S14702045(09)70026-9

37 Schwarze JE, Valdebenito P, Ortega C, Villa S, Crosby J, Pommer R. Do women offered assisted reproduction technologies have a higher incidence of gynecologic cancer? A systematic review and metaanalysis. JBRA Assist Reprod 2017;21:115-9. doi:10.5935/15180557.20170026

38 Jones ME, Swerdlow AJ. Bias in the standardized mortality ratio when using general population rates to estimate expected number of deaths. Am J Epidemiol 1998;148:1012-7. doi:10.1093/ oxfordjournals.aje.a009567

Supplementary appendix: figures S1 and S2, boxes S1 and S2, and tables S1-S6 